\title{
Electron-donor function of methanofullerenes in donor-acceptor bulk heterojunction systems $\dagger$
}

Cite this: Chem. Commun., 2014 50, 4123

Received 5th February 2014

Accepted 26th February 2014

DOI: $10.1039 / \mathrm{c} 4 \mathrm{cc} 00940 a$

www.rsc.org/chemcomm

Electron-donor function of methanofullerenes (MFs) in bulk heterojunction systems is demonstrated by the combination of MFs with the electron-transporting $\pi$-system that has a much higher electron affinity than MFs.

Fullerene derivatives have been well-recognized as electron-accepting materials and extensively used in donor-acceptor linked systems in order to investigate a photoinduced charge-separation process in the molecular level. ${ }^{1}$ This fundamental aspect is extended to the photonto-current conversion process in bulk composite devices. In fact, organic photovoltaics (OPVs) have become an active area of research in both academia and industry in recent years. ${ }^{2}$ The most efficient organic layers for OPVs are based on the concept of bulk heterojunctions (BHJs), which are composed of a blend of electron-donor (p-type) and electron-acceptor (n-type) materials. ${ }^{3}$ Methanofullerene derivatives represented by $[6,6]$-phenyl- $\mathrm{C}_{x}$-butyric acid methyl ester $\left(x=61: \mathrm{PC}_{61} \mathrm{BM}, x=71: \mathrm{PC}_{71} \mathrm{BM}\right)$ have been employed as typical acceptor semiconductors in such systems (Fig. 1). ${ }^{4}$ On the other hand, the hole-transporting characteristics of the methanofullerenes in bulk heterojunction films remain unclear, although there have been several reports suggesting that fullerene derivatives participate in not only electron transportation but also hole transportation in donor polymer- $\mathrm{PC}_{61} \mathrm{BM}$ blend films. ${ }^{5,6}$ Considering that $\mathrm{PC}_{61} \mathrm{BM}$ shows ambipolar charge-transport characteristics, ${ }^{7}$ it should also be able to function as a donor semiconductor when combined with acceptor materials whose low-lying lowest unoccupied molecular

\footnotetext{
${ }^{a}$ The Institute of Scientific and Industrial Research (ISIR), Osaka University, 8-1 Mihogaoka, Ibaraki, Osaka 567-0047, Japan.

E-mail: yutakaie@sanken.osaka-u.ac.jp, aso@sanken.osaka-u.ac.jp

${ }^{b}$ Japan Science and Technology Agency (JST)-PRESTO, 4-1-8 Honcho, Kawaguchi, Saitama 333-0012, Japan

${ }^{c}$ Institute for Chemical Research, Kyoto University, Uji, Kyoto 611-0011, Japan

${ }^{d}$ Department of Applied Chemistry, Graduate School of Engineering,

Osaka University, 2-1 Yamadaoka, Suita, Osaka 565-0871, Japan

${ }^{e}$ Department of Polymer Chemistry, Graduate School of Engineering,

Kyoto University, Katsura, Nishikyo, Kyoto 615-8510, Japan

$\dagger$ Electronic supplementary information (ESI) available: LEIP, PESA, TRMC, SCLC, and UV-vis measurements; detailed measurement conditions. See DOI: 10.1039/c4cc00940a
}

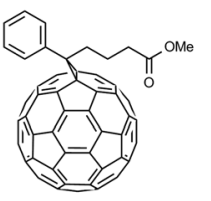

$\mathrm{PC}_{61} \mathrm{BM}$
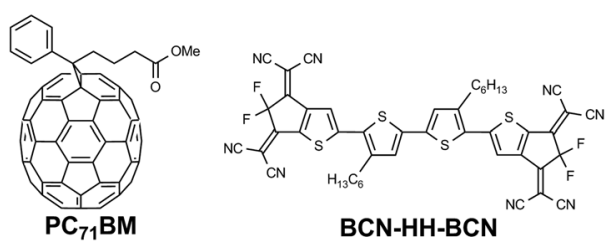

BCN-HH-BCN
Fig. 1 Chemical structures of the compounds used in this study

orbital (LUMO) energy levels are much lower than that of $\mathrm{PC}_{61} \mathrm{BM}$. Nevertheless, the use of fullerene derivatives as donor materials is limited to the combination of fullerene $\left(\mathrm{C}_{60}\right) /$ perfluorinated phthalocyanine derivatives in vacuum-deposited bilayer OPV devices. ${ }^{8,9}$ In addition, the confined interfaces between the donor and acceptor materials in such bilayer systems hinder spectroscopic investigations.

In order to realize $\mathrm{BHJ}$ systems that employ $\mathrm{PC}_{61} \mathrm{BM}$ as the donor material, it is necessary to use acceptor materials with low LUMO energy levels, high electron mobilities, and good solubilities. Recently, we developed a new electron-transporting $\pi$-conjugated compound (BCN-HH-BCN) that meets these criteria (Fig. 1). ${ }^{10}$ We envisioned that using $\mathrm{BCN}-\mathrm{HH}-\mathrm{BCN}$ in combination with $\mathrm{PC}_{61} \mathrm{BM}$ should allow the electron-donor function and hole-transporting characteristics of $\mathrm{PC}_{61} \mathrm{BM}$ in blend films to be elucidated. In this communication, we systematically investigated the material properties, the photovoltaic characteristics of $\mathrm{BHJ}$ solar cells based on $\mathrm{PC}_{61} \mathrm{BM}$ and $\mathrm{BCN}-\mathrm{HH}-\mathrm{BCN}$, and the charge carrier dynamics in the corresponding blend films.

Previously, the electrochemical properties of $\mathrm{BCN}-\mathrm{HH}-\mathrm{BCN}$ were investigated by cyclic voltammetry measurements performed in a fluorobenzene solution. ${ }^{10}$ On the basis of its half-wave reduction potential $\left(-0.67 \mathrm{~V} v \mathrm{vs} . \mathrm{Fc} / \mathrm{Fc}^{+}\right)$and considering that the energy level of ferrocene/ferrocenium $\left(\mathrm{Fc} / \mathrm{Fc}^{+}\right)$is $-4.8 \mathrm{eV}$ below the vacuum level, the LUMO energy level of $\mathrm{BCN}-\mathrm{HH}-\mathrm{BCN}$ was estimated to be $-4.1 \mathrm{eV}$. Although this method is widely used for estimating HOMO and LUMO energies, the values determined by this method are for isolated single molecules in solution only. In addition, these values depend on a number of factors such as different approximations of the formal potential of $\mathrm{Fc} / \mathrm{Fc}^{+}{ }^{+11}$ Recently, low-energy inverse photoemission spectroscopy (LEIPS) has been demonstrated. It involves the use of irradiating electrons with kinetic energies lower than the damage 
(a)

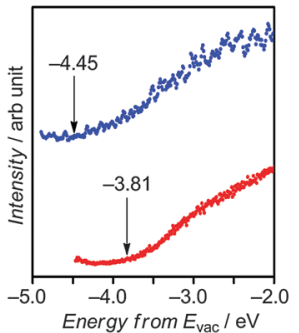

(b)

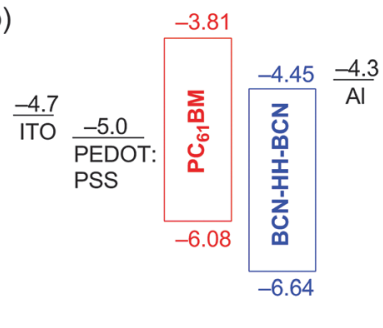

Fig. 2 (a) LEIP spectra of $\mathrm{BCN}-\mathrm{HH}-\mathrm{BCN}$ (blue) and $\mathrm{PC}_{61} \mathrm{BM}$ (red). ${ }^{12 b}$ (b) Energy level diagrams for $\mathrm{BCN}-\mathrm{HH}-\mathrm{BCN}$ and $\mathrm{PC}_{61} \mathrm{BM}$. The $\mathrm{HOMO}$ and LUMO energy levels were determined by the PESA and LEIPS, respectively.

threshold of organic materials. ${ }^{12 a}$ The photon energy falls in the nearultraviolet range, allowing one to use a multilayer bandpass filter for photon detection. This leads to an overall energy resolution of $0.3 \mathrm{eV}$ or better. In this study, we applied this new technique to determine the LUMO energy level of BCN-HH-BCN in the solid state. Fig. 2(a) shows the LEIP spectra of BCN-HH-BCN and $\mathrm{PC}_{61} \mathrm{BM}$ obtained at a photon energy of $5.0 \mathrm{eV}$. On the basis of the onset energy with respect to the vacuum level, the electron affinity of BCN-HH-BCN in the solid state is determined to be $-4.45 \mathrm{eV}$ (see also Fig. S1 in the ESI $\dagger$ ). Since the electron affinity of $\mathrm{PC}_{61} \mathrm{BM}$ was recently determined to be $-3.81 \mathrm{eV}$ by the same technique, ${ }^{12 b}$ as shown in Fig. 2(a), the LUMO energy level of $\mathrm{BCN}-\mathrm{HH}-\mathrm{BCN}$ is $0.64 \mathrm{eV}$ lower than that of $\mathrm{PC}_{61} \mathrm{BM}$.

The ionization potentials (IPs) of $\mathrm{BCN}-\mathrm{HH}-\mathrm{BCN}$ and $\mathrm{PC}_{61} \mathrm{BM}$ films were measured by photoelectron spectroscopy in air (PESA). The IP for BCN-HH-BCN was determined to be $-6.64 \mathrm{eV}$, which is $0.56 \mathrm{eV}$ lower than that of $\mathrm{PC}_{61} \mathrm{BM}$ (Fig. S2, ESI†). On the basis of these results, the energy levels of $\mathrm{BCN}-\mathrm{HH}-\mathrm{BCN}$ and $\mathrm{PC}_{61} \mathrm{BM}$ were unambiguously determined and are depicted in Fig. 2(b); it can be inferred that BCN-HH-BCN is a good candidate for an acceptor material to cause the donor function of $\mathrm{PC}_{61} \mathrm{BM}$.

The local hole mobility of $\mathrm{PC}_{61} \mathrm{BM}$ was investigated by flashphotolysis time-resolved microwave conductivity (FP-TRMC). ${ }^{13}$ As shown in Fig. S3(a) (ESI $\dagger$ ), the photoconductivity transient of a $\mathrm{PC}_{61} \mathrm{BM}$ film prepared by the drop casting of a $\mathrm{PC}_{61} \mathrm{BM}$ solution in tetrahydrofuran (THF) and excited at $355 \mathrm{~nm}$ displays a maximum $\phi \Sigma \mu$ of $2.6 \times 10^{-5} \mathrm{~cm}^{2} \mathrm{~V}^{-1} \mathrm{~s}^{-1}$, where $\phi$ and $\Sigma \mu$ denote the charge carrier generation yield and the sum of the hole and electron mobilities $\left(\Sigma \mu=\mu^{+}+\mu^{-}\right)$, respectively. Upon the addition of tetracyanoethylene (TCNE) in the blend ratio of $\mathrm{PC}_{61} \mathrm{BM} / \mathrm{TCNE}=1: 0.1$ by weight, the maximum $\phi \Sigma \mu$ was increased to $3.2 \times 10^{-5} \mathrm{~cm}^{2} \mathrm{~V}^{-1} \mathrm{~s}^{-1}$. This is due to electron transfer from $\mathrm{PC}_{61} \mathrm{BM}$ to TCNE, which acts as a strong electron acceptor against not only donor polymers (e.g., poly(3-hexylthiophene) $)^{14 a}$ but also $\mathrm{PC}_{61} \mathrm{BM}^{6 a}$ Concomitantly, the photocurrent, measured using a comb-type interdigitated $\mathrm{Au}$ electrode on glass, increased by $65 \%$, as shown in Fig. S3(b) (ESI†). Because the amount of TCNE added is low (10\%) and since TCNE lacks an effective electron transporting pathway, the increases in both the FP-TRMC and the photocurrent transients are most likely because of the photogenerated holes in $\mathrm{PC}_{61} \mathrm{BM}$. By estimating $\phi$ using a previously reported procedure, ${ }^{14 b}$ the local hole mobility of $\mathrm{PC}_{61} \mathrm{BM}$ is found to be $8 \times 10^{-3} \mathrm{~cm}^{2} \mathrm{~V}^{-1} \mathrm{~s}^{-1}$. Meanwhile, the electron mobility in pristine $\mathrm{PC}_{61} \mathrm{BM}$, obtained in the same fashion, was $0.02 \mathrm{~cm}^{2} \mathrm{~V}^{-1} \mathrm{~s}^{-1}$ and in agreement with that reported previously $\left(0.04-0.3 \mathrm{~cm}^{2} \mathrm{~V}^{-1} \mathrm{~s}^{-1}\right)$ using pulse radiolysis TRMC. ${ }^{7 b}$ The fact that

the hole mobility of $\mathrm{PC}_{61} \mathrm{BM}$ is lower than its electron mobility as well as its deep LUMO is indicative of the primary n-type nature of $\mathrm{PC}_{61} \mathrm{BM}$; this property is the reason it is commonly used in OPVs and field-effect transistors. However, $\mathrm{PC}_{61} \mathrm{BM}$ is potentially able to serve as a donor in combination with a much stronger electron acceptor.

In order to investigate the photovoltaic properties of a blend of $\mathrm{PC}_{61} \mathrm{BM}$ and $\mathrm{BCN}-\mathrm{HH}-\mathrm{BCN}$, a conventional $\mathrm{BHJ}$ solar cell was fabricated. The current density-voltage $(J-V)$ characteristics of the device were evaluated under air mass 1.5 global (AM1.5G) simulated solar illumination with an irradiation intensity of $100 \mathrm{~mW} \mathrm{~cm}{ }^{-2}$. The configuration of the cell was as follows: glass/indium tin oxide (ITO)/ poly(3,4-ethylenedioxythiophene):poly(styrenesulfonate)(PEDOT:PSS)/ active layer/Al. The conditions for fabricating the active layer were optimized and found that an active layer could be prepared by spin coating an $o$-dichlorobenzene solution of the $\mathrm{PC}_{61} \mathrm{BM} / \mathrm{BCN}-\mathrm{HH}-\mathrm{BCN}$ ( $2: 1$ weight ratio) blend in a nitrogen atmosphere without thermal annealing (see the ESI $\dagger$ ). Under these optimized conditions, the OPV device exhibited a short-circuit current $\left.U_{\mathrm{sC}}\right)$ of $1.73 \mathrm{~mA} \mathrm{~cm}{ }^{-2}$, an open-circuit voltage $\left(V_{\mathrm{OC}}\right)$ of $0.45 \mathrm{~V}$, a fill factor $(\mathrm{FF})$ of 0.27 , and a PCE of $0.21 \%$ (Fig. 3(a)). The photocurrent action spectrum of the external quantum efficiency (EQE) of the device was measured to reveal its photoresponse against different wavelengths. As shown in Fig. 3(b), the EQE spectrum of the device exhibited a broad response in the range of $300-750 \mathrm{~nm}$. This profile resembled well the absorption spectrum of a $\mathrm{PC}_{61} \mathrm{BM} / \mathrm{BCN}-\mathrm{HH}-\mathrm{BCN}(2: 1)$ blend film (Fig. S4(a), $\mathrm{ESI}+$ ). On the basis of the absorption spectra of $\mathrm{PC}_{61} \mathrm{BM}$ and $\mathrm{BCN}-$ HH-BCN in the solid state (Fig. S4(b), ESI†), it can be said that the photoresponses of the device in the short-wavelength region of approximately $400 \mathrm{~nm}$ and the long-wavelength region extending from 500 to $750 \mathrm{~nm}$ are mainly derived from $\mathrm{PC}_{61} \mathrm{BM}$ and $\mathrm{BCN}-\mathrm{HH}-$ $\mathrm{BCN}$, respectively. This indicates that, on being photoexcited, both $\mathrm{PC}_{61} \mathrm{BM}$ and $\mathrm{BCN}-\mathrm{HH}-\mathrm{BCN}$ contributed to the photocurrent generated. Furthermore, as shown in Fig. 3(a), the PCE was improved to $0.34 \%$ for the OPV device based on $\mathrm{PC}_{71} \mathrm{BM}$ and BCN-HH-BCN (2:1): a $J_{\mathrm{SC}}$ of $2.17 \mathrm{~mA} \mathrm{~cm}{ }^{-2}$, a $V_{\mathrm{OC}}$ of $0.53 \mathrm{~V}$, and a FF of 0.29 . The EQE spectrum of the $\mathrm{PC}_{71} \mathrm{BM}$-containing device showed a higher efficiency in the visible region than that of the $\mathrm{PC}_{61} \mathrm{BM}$-containing device (Fig. 3(a)), reflecting the relatively high absorbance of $\mathrm{PC}_{71} \mathrm{BM}$ (Fig. $\mathrm{S} 4(\mathrm{a}), \mathrm{ESI}+$ ). In addition, hole-only devices with a structure of ITO/PEDOT:PSS/PC ${ }_{61} \mathrm{BM}$ or $\mathrm{PC}_{71} \mathrm{BM} / \mathrm{Au}$ showed that the space-charge-limited current (SCLC) hole mobility of $\mathrm{PC}_{71} \mathrm{BM}\left(1.6 \times 10^{-6} \mathrm{~cm}^{2} \mathrm{~V}^{-1} \mathrm{~s}^{-1}\right)$ was slightly higher than that of $\mathrm{PC}_{61} \mathrm{BM}\left(1.4 \times 10^{-6} \mathrm{~cm}^{2} \mathrm{~V}^{-1} \mathrm{~s}^{-1}\right)$ (Fig. S5, ESI $\dagger$ ). This result also supports the improved performance of the $\mathrm{PC}_{71} \mathrm{BM}-$ containing device.
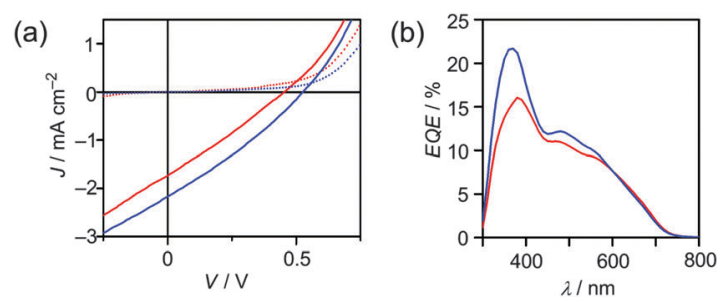

Fig. 3 (a) J-V curves of the OPV device based on $\mathrm{PC}_{61} \mathrm{BM}-\mathrm{BCN}-\mathrm{HH}-$ $\mathrm{BCN}$ (red) and $\mathrm{PC}_{71} \mathrm{BM}-\mathrm{BCN}-\mathrm{HH}-\mathrm{BCN}$ (blue) under $\mathrm{AM} 1.5 \mathrm{G}$ illumination (100 $\mathrm{mW} \mathrm{cm}^{-2}$ ) and in the dark (dotted lines). (b) EQE spectra of the OPV device based on $\mathrm{PC}_{61} \mathrm{BM}-\mathrm{BCN}-\mathrm{HH}-\mathrm{BCN}$ (red) and $\mathrm{PC}_{71} \mathrm{BM}-\mathrm{BCN}-\mathrm{HH}-\mathrm{BCN}$ (blue). 


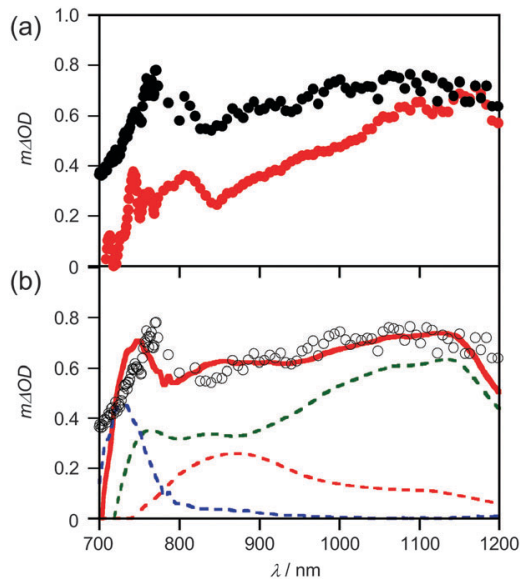

Fig. 4 (a) TAS of the $\mathrm{PC}_{61} \mathrm{BM}-\mathrm{BCN}-\mathrm{HH}-\mathrm{BCN}$ blend film $0.1 \mathrm{~ns}$ (black) and $1 \mathrm{~ns}$ (red) after laser excitation at $600 \mathrm{~nm}$. The laser fluence was set to $30 \mu \mathrm{J} \mathrm{cm}{ }^{-2}$. (b) The simulation of TAS. The open circles indicate the spectrum measured $0.1 \mathrm{~ns}$ after excitation. The red solid line indicates the spectrum simulated by summing the individual absorption spectrum of the transient species: $\mathrm{PC}_{61} \mathrm{BM}$ radical cations (red dashed line), $\mathrm{BCN}-\mathrm{HH}-\mathrm{BCN}$ radical anions (blue dashed line), and $\mathrm{BCN}-\mathrm{HH}-\mathrm{BCN}$ triplet excitons (green dashed line).

We measured the transient absorption spectra (TAS) of the $\mathrm{PC}_{61} \mathrm{BM}-\mathrm{BCN}-\mathrm{HH}-\mathrm{BCN}$ blend film to elucidate its charge generation dynamics. As shown in Fig. 4(a), 0.1 ns after the laser excitation, a sharp absorption peak was observed at approximately $700 \mathrm{~nm}$. In addition, a broad absorption band was observed extending from 900 to $1200 \mathrm{~nm}$. The absorption band at 700-900 $\mathrm{nm}$ disappeared gradually and instead an absorption band was observed at approximately $1100 \mathrm{~nm}$ at $1 \mathrm{~ns}$ after the excitation. In order to assign these absorption bands, we measured the absorption spectra of the BCNHH-BCN singlet excitons, triplet excitons, and radical anions separately (see the ESI†). Consequently, we found that the BCN-HH-BCN radical anions, singlet excitons, and triplet excitons exhibit absorption bands at 720, 950, and $1100 \mathrm{~nm}$, respectively. As reported previously, $\mathrm{PC}_{61} \mathrm{BM}$ radical cations exhibit an absorption band at $890 \mathrm{~nm} .{ }^{6 a}$ On the basis of this fact, the transient spectrum at $0.1 \mathrm{~ns}$ could be replicated by summing the individual spectrum of the $\mathrm{PC}_{61} \mathrm{BM}$ radical cations, the $\mathrm{BCN}-\mathrm{HH}-\mathrm{BCN}$ radical anions, and the $\mathrm{BCN}-\mathrm{HH}-$ BCN triplet excitons, as shown in Fig. 4(b). This finding clearly shows that $\mathrm{PC}_{61} \mathrm{BM}$ radical cations and $\mathrm{BCN}-\mathrm{HH}-\mathrm{BCN}$ radical anions are generated in the blend upon photoexcitation. On the other hand, the transient spectrum at $1 \mathrm{~ns}$ was almost identical to the absorption spectrum of the BCN-HH-BCN triplet excitons. This triplet formation cannot be ascribed to the intersystem crossing because $\mathrm{BCN}-\mathrm{HH}-\mathrm{BCN}$ singlet excitons disappeared in $2 \mathrm{ps}$ in $\mathrm{PC}_{61} \mathrm{BM}-\mathrm{BCN}-\mathrm{HH}-\mathrm{BCN}$ films. Rather, it is ascribed to the triplet formation through the charge recombination of $\mathrm{PC}_{61} \mathrm{BM}$ radical cations and $\mathrm{BCN}-\mathrm{HH}-\mathrm{BCN}$ radical anions. This is probably because $\mathrm{BCN}-\mathrm{HH}-\mathrm{BCN}$ triplet excitons are more stable than both $\mathrm{PC}_{61} \mathrm{BM}$ radical cations and $\mathrm{BCN}-\mathrm{HH}-\mathrm{BCN}$ radical anions. The triplet energy $\left(E_{\mathrm{T}}\right)$ of $\mathrm{BCN}-\mathrm{HH}-\mathrm{BCN}$ is roughly estimated to be $1.1 \mathrm{eV}$, assuming that the difference in the energies of singlet and triplet excitons is $0.7 \mathrm{eV}$, which is the typical value for small molecules. ${ }^{15}$ On the other hand, the triplet energy of $\mathrm{PC}_{61} \mathrm{BM}$ is reported to be $1.5 \mathrm{eV}^{16}$ The energy of the charge-separated states $\left(E_{\mathrm{CT}}\right)$ was estimated to be $1.63 \mathrm{eV}$ from the HOMO $\left(\mathrm{PC}_{61} \mathrm{BM}\right)$ and LUMO (BCN-HH-BCN) levels shown in Fig. 2(b). We, therefore, conclude that $\mathrm{PC}_{61} \mathrm{BM}$ radical cations and $\mathrm{BCN}-\mathrm{HH}-\mathrm{BCN}$ radical anions are generated in the blend but are converted to the more stable BCN-HH-BCN triplet states by charge recombination. This formation of the triplet states is consistent with the relatively low device performance of the $\mathrm{PC}_{61} \mathrm{BM}-\mathrm{BCN}-\mathrm{HH}-\mathrm{BCN}$ solar cells.

In summary, we unambiguously determined the molecular properties of $\mathrm{PC}_{61} \mathrm{BM}$ and $\mathrm{BCN}-\mathrm{HH}-\mathrm{BCN}$ in the solid state. The results obtained suggest that $\mathrm{PC}_{61} \mathrm{BM}$ should function as a donor semiconductor when paired with a strong acceptor BCN-HH-BCN. As a consequence, BHJ solar cells based on a combination of $\mathrm{PC}_{x} \mathrm{BM}(x=61$ or 71$)$ and $\mathrm{BCN}-\mathrm{HH}-\mathrm{BCN}$ showed photovoltaic characteristics. The transient absorption measurements of the blend film suggested the formation of $\mathrm{PC}_{61} \mathrm{BM}$ radical cations and BCN-HH-BCN radical anions. The most notable point in this study is that methanofullerene derivatives can contribute to hole transportation as p-type materials in $\mathrm{BHJ}$ systems, which provides important insights into the precise molecular design of semiconducting materials and/or new donor-acceptor systems.

This work was supported by the funding program, JST, JSPS, and MEXT, Japan. We thank Prof. Y. Murata and Dr A. Wakamiya of Kyoto University for PESA measurements.

\section{Notes and references}

1 H. Imahori and S. Fukuzumi, Adv. Funct. Mater., 2004, 14, 525; D. M. Guldi, B. M. Illescas, C. M. Atienza, M. Wielopolski and N. Martin, Chem. Soc. Rev., 2009, 38, 1587; F. D'Souza and O. Ito, Chem. Commun., 2009, 4913.

2 Y. Li, Acc. Chem. Res., 2012, 45, 723; A. Green, K. Emery, Y. Hishikawa, W. Warta and E. D. Dunlop, Prog. Photovoltaics, 2013, 21, 1.

3 G. Yu, J. Gao, J. C. Hummelen, F. Wudl and A. J. Heeger, Science, 1995, 270, 1789; M. Hiramoto, H. Fujiwara and M. Yokoyama, Appl. Phys. Lett., 1991, 58, 1062.

4 M. M. Wienk, J. M. Kroon, W. J. H. Verhees, J. Knol, J. C. Hummelen, P. A. van Hal and R. A. J. Janssen, Angew. Chem., Int. Ed., 2003, 42, 3371; Y. He and Y. Li, Phys. Chem. Chem. Phys., 2011, 13, 1970; Y. Matsuo, Chem. Lett., 2012, 41, 754.

5 C. Melzer, E. J. Koop, V. D. Mihailetchi and P. W. M. Blom, Adv. Funct. Mater., 2004, 14, 865; S. M. Tuladhar, D. Poplavskyy, S. A. Choulis, J. R. Durrant, D. D. C. Bradley and J. Nelson, Adv. Funct. Mater., 2005, 15, 1171; A. Gadisa, K. Tvingstedt, K. Vandewal, F. Zhang, J. V. Manca and O. Inganäs, Adv. Mater., 2010, 22, 1008.

6 (a) S. Yamamoto, J. Guo, H. Ohkita and S. Ito, Adv. Funct. Mater., 2008, 15, 2555; (b) S. Yamamoto, H. Ohkita, H. Benten and S. Ito, Adv. Funct. Mater., 2012, 22, 3075.

7 (a) T. D. Anthopoulos, C. Tanase, S. Setayesh, E. J. Meijer, J. C. Hummelen, P. W. M. Blom and D. M. de Leeuw, Adv. Mater., 2004, 16, 2174; (b) M. P. de Haas, J. M. Warman, T. D. Anthopoulos and D. M. de Leeuw, Adv. Funct. Mater., 2006, 16, 2274.

8 Q. L. Song, H. B. Yang, Y. Gan, C. Gong and C. M. Li, J. Am. Chem. Soc., 2010, 132, 4554; J. L. Yang, P. Sullivan, S. Schumann, I. Hancox and T. S. Jones, Appl. Phys. Lett., 2012, 100, 023307.

9 Metal-doped $\mathrm{C}_{60}$ can also function as a donor: M. Kubo, K. Iketaki, T. Kaji and M. Hiramoto, Appl. Phys. Lett., 2011, 98, 073311.

10 Y. Ie, K. Nishida, M. Karakawa, H. Tada, A. Asano, A. Saeki, S. Seki and Y. Aso, Chem.-Eur. J., 2011, 17, 4750.

11 C. M. Cardona, W. Li, A. E. Kaifer, D. Stockdale and G. C. Bazan, Adv. Mater., 2011, 23, 2367.

12 (a) H. Yoshida, Chem. Phys. Lett., 2012, 539-540, 180; (b) H. Yoshida, MRS Proc., 2012, 1493, 295.

13 A. Saeki, Y. Koizumi, T. Aida and S. Seki, Acc. Chem. Res., 2012, 45, 1193. 14 (a) A. Saeki, S. Seki, Y. Koizumi, T. Sunagawa, K. Ushida and S. Tagawa, J. Phys. Chem. B, 2005, 109, 10015; (b) Y. Yasutani, A. Saeki, T. Fukumatsu, Y. Koizumi and S. Seki, Chem. Lett., 2013, 42, 19.

15 A. Köhler and H. Bässler, Mater. Sci. Eng., R, 2009, 66, 71.

16 S. Cook, H. Ohkita, J. R. Durrant, Y. Kim, J. J. Benson-Smith, J. Nelson and D. D. C. Bradley, Appl. Phys. Lett., 2006, 89, 101128. 